\title{
Phosphoglucose Isomerase Variability in Sympatric Populations of Mediterranean Species of Patella (Gastropoda, Prosobranchiata)
}

\author{
G. Badino and G. Sella \\ Istituto di Zoologia dell'Università, Via Accademia Albertina 17, Torino, Italy
}

\begin{abstract}
Genetic variability at the phosphoglucose isomerase (PGI) locus was compared in Mediterranean sympatric populations of Patella aspera, P. coerulea and P. lusitanica. P. aspera and $P$. coerulea show PGI patterns much alike, while $P$. lusitanica exhibits a more anodal general zone of mobility of its PGI allozymes. The differentiation of $P$. Iusitanica pattern may be tentatively interpreted as the result of a selective action, which enabled this species to extend its range in the upper intertidal zone. However, all the most frequent PGI allozymes of the Mediterranean Patella species exhibited the same degree of thermostability. Such findings suggest that, in the differentiation process of the PGI locus in Mediterranean limpets, one or more factors other than temperature may have been involved.
\end{abstract}

\section{INTRODUCTION}

Patella lusitanica Gmelin, P. aspera Lamarck and $P$. coerulea L. are the three Patella species commonly occurring on the rocky shores of the Mediterranean Sea. Patella lusitanica - according to Pérès and Picard (1964) the ecological equivalent of Atlantic $P$. vulgata in the Mediterranean Sea - occurs mainly in the upper intertidal zone. $P$. aspera colonizes the lower part of the same zone, and $P$. coerulea the upper infralittoral zone. However, in the same localities along the Tyrrhenian coasts, due to the restricted breadth of the intertidal zone, these three species, by widening their vertical range to some extent, may coexist. Specifically, at Leghorn, these three species are associated together in the lower intertidal zone and P. aspera is found along with $P$. coerulea below the low-tide mean level.

The shell of the Mediterranean populations of Patella lusitanica appears to be consistently invariable; this facilitates the identification of this species. On the contrary it is difficult to separate $P$. aspera from $P$. coerulea only on the basis of shell features, because these are very similar in both species (Evans, 1958; Sella and Bacci, 1971). Some characteristics of the shell can be partly related to the environment in which the limpets live. The phenotypic variation in $P$. coerulea was seen, in fact, to be higher in the specimens collected in the intertidal sheltered zones (Bacci and Sella, 1970), where different microhabitats are more likely to be formed, compared to the specimens collected either in intertidal exposed zones or in infralittoral zones (Sella and Bacci, 1971).

As in other species within the genus Patella (Brian and Owen, 1952; Vermeij, 1973), also in the Mediterranean ones, the shell parameters and the radula-fraction reflect the different habitats and consequent adaptations of the limpets, mainly to dessication (Davies, 1969; Bannister, 1975; Sella, 1976).

The present work investigates the genetic variability among the mediterranean limpets, by examining the locus of phosphoglucose isomerase (PGI) in coexisting populations of Patella aspera, $P$, coerulea and $P$. Iusitanica. This enzyme, whose variability was studied by Wilkins (1977) in $P$. vulgata and in Atlantic populations of $P$. aspera, is active in the anaerobic phase of respiration. According to Davies $(1967,1969)$ the respiration rate in limpets is inversely related to their vertical distribution on the shore and hence to the temperature. On the other hand, according to Branch and Newell (1978), rather than to tidal level, the limpet respiratory metabolism is correlated with food availability.

\section{MATERIALS AND METHODS}

Sampling of the limpets was carried out in January, April and September 1978 at Leghorn (Tuscany), in the intertidal zone, down to a depth of $4 \mathrm{~m}$, where only 
Patella aspera and $P$. coerulea were present. For comparative analysis, an intertidal sample of $P$. vilgata was also collected at Roscoff (Brittany) in May 1978. Limpets were carried alive to our laboratory in Torino. The different species were determined by morphological examination of mono- and pluri-cuspid radula teeth, according to the method suggested by FischerPiette and Gaillard (1959).

\section{Morphometric Analysis}

In each specimen we measured radula length and calculated relative shell height $\left(h_{s h}\right)$, which is defined as the ratio of shell height (h) over the geometrical mean of the major diameter (l) and of the minor diameter (w) of the shell base:

$$
h_{s h}=\frac{h}{(l w)^{1 / 2}}
$$

Such ratio is considered the best way to describe morphological gradients in relation to shore level (Vermeij, 1973).

In order to assess the degree of morphometrical overlap between pairs of populations, biometrical differences were evaluated by a discriminant function, based on measurements of radula lengths and of $h_{\text {sh }}$ values of relative shell heights. The values given by the discriminant functions $(D)$ were used as index of distance between the pairs of compared populations (Snedecor and Cochran, 1967).

\section{Electrophoretic Methods}

Foot muscles and mantles were excised, homogenized together in an equal volume of distilled water with a refrigerated glass homogenizer, and centrifuged at $4{ }^{\circ} \mathrm{C}$ first for $10 \mathrm{~min}$ at $6,000 \mathrm{rpm}$ and then for $5 \mathrm{~min}$ at 12,000 rpm. $0.01 \mathrm{M}$ Tris-borate buffer $(\mathrm{pH}=8)$ was added to the supernatant $(1: 1)$.

The samples were all run on ${ }^{\mathrm{R}}$ Cellogel cellulose acetate strips (Labormetrics, Milano) after ascertaining that such strips yielded identical results with respect to the polyacrylamide gel slabs. The ${ }^{\mathrm{R}}$ Cellogel method, thanks to its simple and rapid employment, was found expedient for the routine study of PGI in Patella. The electrode buffer was $0.1 \mathrm{M}$ Tris-borate $(\mathrm{pH}=8)$. PGI activity was detected by the methods of Schaal and Anderson (1974).

\section{PGI Heat-Sensitivity Tests}

These experiments were carried out on 6 individuals of Patella aspera, 6 of $P$. coerulea, 4 of $P$. lusitanica, and 4 of $P$. vulgata, exhibiting the most frequent alleles for each species, in homozygous combination. Foot muscle and mantle extract from each individual, centrifuged and diluted (3:1) by $0.01 \mathrm{M}$ Tris-borate buffer $(\mathrm{pH}=8)$, was divided into two aliquots, one of which was used as control, the other incubated in a water bath for different periods at $47^{\circ}, 50^{\circ}$ or $55^{\circ} \mathrm{C}$. Following incubation, each sample was cooled and subjected to cellulose acetate electrophoresis, side by side with its control. The strips were stained in the usual manner at room temperature. PGI relative activity was judged by the intensity of formazan deposition.

\section{RESULTS}

In the three Mediterranean Patella species, as in $P$. vulgata, a single region of electrophoretic activity is exhibited by PGI. Such region is characterized by a more or less extensive polymorphism according to the species.

Each individual shows either a single or three electrophoretic bands. These observations lead us to infer that the enzyme is encoded at a single locus; that phenotypes having a single band correspond to homozygous genotypes, while three-banded phenotypes correspond to heterozygous genotypes (Fig. 1). As in

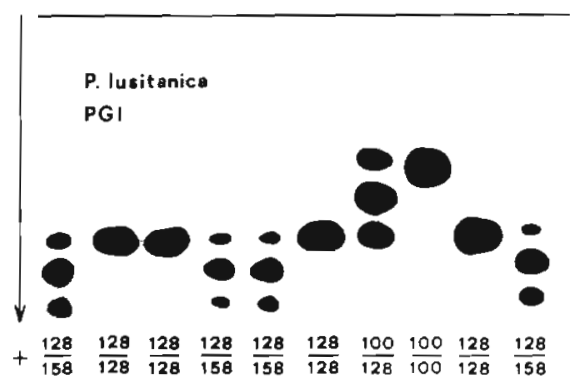

Fig. 1. Patella lusitanica. PGI phenotypes observed in Leghorn population

other marine molluscs the PGI active form is a dimer (Levinton, 1973; Snyder and Gooch, 1973; Wilkins and Mathers, 1974; Levinton, 1975; Wilkins, 1975; Tracey et al., 1975).

\section{Patella aspera and P. coerulea}

In Patella aspera, 5 codominant alleles are expressed at the PGI locus, three of which have a frequency below 0.05. All these alleles, except one of the most rare, control phenotypes that are not electrophoretically distinguishable from those of $P$. coerulea (Fig. 2 and Table 1). $\mathrm{Pgi}^{-100}$ indicates the more frequent allele in $P$. aspera (the more common in $P$. coerulea as well); 
Table 1. Summary of allele frequencies at the PGI locus in Patella species. PGI alleles are ordered from slow to fast mobility enzyme variants. $\mathrm{N}$ : number of individuals tested. $\mathrm{n}_{e}$ : effective numbers of alleles

\begin{tabular}{|lrccccccccc|}
\hline Species & $\mathrm{N}$ & 68 & 72 & 80 & 100 & 108 & 123 & 128 & 158 & $\mathrm{n}_{\mathrm{e}}$ \\
\hline P. aspera & 84 & 0.036 & 0.226 & 0.012 & 0.714 & - & 0.012 & - & - & 1.805 \\
$P$. coenulea & 100 & 0.010 & 0.135 & - & 0.840 & - & 0.020 & - & - & 1.387 \\
$P$. lusitanica & 46 & - & - & - & 0.109 & 0.011 & - & 0.717 & 0.163 & 1.809 \\
$P$. vulgata & 70 & - & - & - & 0.007 & - & - & 0.986 & 0.007 & 1.028 \\
\hline
\end{tabular}

Table 2. Distribution of observed and expected PGI phenotypes in Patella species, and $X^{2}$ values from test of goodness of fit to expected distributions

\begin{tabular}{|c|c|c|c|c|}
\hline Phenotypes & P. aspera & P. coerulea & P. Iusitanica & P. vulgata \\
\hline $68 / 72$ & $2(1.37)$ & - & - & - \\
\hline $80 / 100$ & $2(1.44)$ & - & - & - \\
\hline $68 / 100$ & $4(4.32)$ & $2(1.68)$ & - & - \\
\hline $72 / 72$ & $8(4.29)$ & $1(1.82)$ & - & - \\
\hline $72 / 100$ & $20(27.12)$ & $24(21.05)$ & - & - \\
\hline $100 / 100$ & $46(42.82)$ & $69(70.56)$ & $1(0.55)$ & - \\
\hline $100 / 123$ & $2(1.44)$ & $4(3.36)$ & - & - \\
\hline $100 / 123$ & - & - & $7(7.20)$ & $1(0.97)$ \\
\hline $108 / 128$ & - & - & $1(0.73)$ & - \\
\hline $128 / 128$ & - & - & $22(23.65)$ & $68(67.2)$ \\
\hline $128 / 158$ & & & $14(10.75)$ & - \\
\hline $100 / 158$ & - & - & $1(1.63)$ & $1(0.97)$ \\
\hline Sample size & 84 & 100 & 46 & 70 \\
\hline$X^{2}$ & 5.315 & 0.185 & 1.550 & 0.010 \\
\hline d. f. & 6 & 3 & 3 & 1 \\
\hline $\mathrm{P}$ & 0.50 & 0.98 & 0.67 & 0.92 \\
\hline \multicolumn{5}{|c|}{ Heterozygosity } \\
\hline observed & 0.357 & 0.300 & 0.500 & 0.028 \\
\hline expected & 0.437 & 0.276 & 0.447 & 0.028 \\
\hline
\end{tabular}

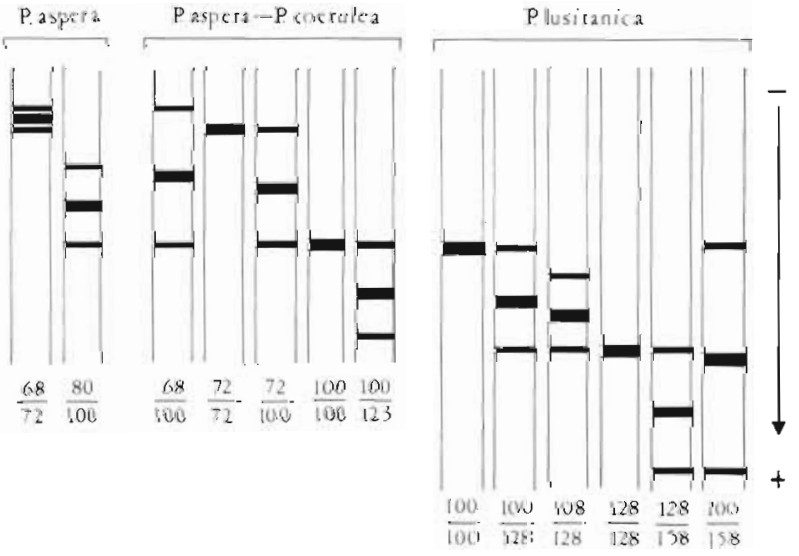

Fig. 2. Drawing of all PGI phenotypes observed in Leghorn populations of three Mediterranean limpets

higher or lower numbers indicate alleles, respectively, coding for electrophoretic fractions more or less mobile than that controlled by the $\mathrm{Pgi}^{-100}$ allele (e.g. the Pgi ${ }^{-80}$ allele codifies for the band having $80 \%$ mobility of band 100 in our electrophoretic system).
Among all possible phenotypes in the sample examined by us, 7 were present in Patella aspera and 5 in P. coerulea (Fig. 2). In both species phenotype distribution is in good agreement with Hardy-Weinberg expectations (for P. aspera: $X_{6}^{2}=5.315, P=0.50$; for $P$. coerulea: $X_{3}^{2}=0.18, P=0.98$ ); the observed and the expected frequencies of the heterozygotes agree quite well (Table 2). The effective allele number ( $n_{e}$, after Kimura and Crow, 1964) is greater for Patella aspera than for $P$. coerulea (Table 1).

The PGI phenotypic distribution in the two species, tested by $2 \times 3$ contingency table, differs significantly at the $0.01-0.02$ level $\left(X_{2}^{2}=8.46\right)$ as well as the $\mathrm{Pgi}^{-100}$ allele distribution $\left(X_{1}^{2}=7.75\right)$.

\section{Patella lusitanica}

In this species, 4 codominant alleles control the expression of the various PGI fractions. Only one of them has a frequency below 0.05 . The allele which, in homozygosity, codifies for the less mobile electrophoretic band is not distinguishable from $\mathrm{Pgi}^{-100}$ of Patella 
aspera and $P$. coerulea (Fig. 2); it is not, however, the more common in this series, its frequency being 0.109 (Table 1). It also appears almost only in heterozygous combination within the Leghorn population; in this sample on the whole 6 phenotypes are present; their distribution agrees with the values predicted by the Hardy-Weinberg equilibrium distribution $\left(X_{3}^{2}=1.55\right.$, $P=0.67)$.

The degree of heterozygosity at this locus is greater in Patella lusitanica than in the other two Mediterranean species (Table 2). The allele effective number $\left(n_{e}\right)$ in $P$. lusitanica is equal to that of $P$, aspera and above that of $P$. coerulea (Table 1).

\section{Patella vulgata}

In the Patella vulgata population from Brittany, studied for comparison, the PGI locus is virtualiy monomorphic; its more common allele has a frequency higher than 0.95 (Ayala et al., 1973). Actually two more alleles were observed, although both extremely rare and only in heterozygous combinations; one of them codifies a band with the same mobility as the $\mathrm{Pgi}^{-100}$ band of the Mediterranean species.

Patella vulgata's most common isozyme exhibits an anodal electrophoretic mobility significantly higher than all the $P$. aspera and $P$. coerulea allozymes and it is electrophoretically indistinguishable from the most frequent allozyme of $P$. Iusitanica. The phenotypic distribution is in good agreement with Hardy-Weinberg expectations $\left(X_{1}^{2}=0.010\right)$.

\section{Heat-Sensitivity Tests}

The allozymes submitted to the heat-sensitivity tests were the most frequent ones in Leghorn populations of Patella, i.e. those encoded by $\mathrm{Pgi}^{-100}, \mathrm{Pgi}^{-72}, \mathrm{Pgi}^{-68}$ alleles of $P$. aspera and $P$. coerulea; by $\mathrm{Pgi}^{-128}$ and $\mathrm{Pgi}^{-100}$ of $P$. lusitanica. The allozyme of $P$. vulgata was that encoded by Pgi-128.

All these allozymes were practically unaffected by pre-incubation at $47^{\circ} \mathrm{C}$ for $15 \mathrm{~min}$, at $50^{\circ} \mathrm{C}$ for 15 and 30 min, at $55^{\circ} \mathrm{C}$ for 15 and $30 \mathrm{~min}$. Their electrophoretic mobility and activity were always the same in preincubated as in control samples.

\section{Morphometric Analysis}

The values of the coefficient of morphometric distance between population pairs indicate a marked morphological overlap of Patella lusitanica with $P$. vulgata $(D=0.65 ; 40 \%$ probability of misclassifica- tion). Such overlap may be an indication of the fact that the $P$. vulgata population from Roscoff and that of $P$. lusitanica from Leghorn had been exposed to equivalent desiccation stresses, to which shell shape and radula length are correlated. The two populations may therefore be considered truly ecologically equivalent. Two by two comparisons between coexisting populations of Mediterranean species show a nearly comparable degree of morphometric overlap among the three species $(D=2-2.5 ; 15 \%$ probability of misclassification), even though below that recorded between $P$. Iusitanica and $P$. vulgata. No clear-cut correlation was found between PGI phenotypes and the shell ornamentation characters, previously studied by Bacci and Sella (1970) in $P$. aspera and $P$. coerulea samples.

\section{DISCUSSION}

Wilkins (1977), who examined genetic variability at the PGI locus in Irish limpets Patella vulgata and $P$. aspera, found that the former was less variable than $P$. aspera. In fact in $P$. vulgata, according to Wilkins, this locus can be regarded as essentially monomorphic (two alleles, one of them very rare), whilst in $P$, aspera it showed two or three alleles. Wilkins (1977) also observed that the nearly single isozyme in $P$. vulgata had a significantly more anodal electrophoretic mobility than any of the allozymes of $P$. aspera.

Among the Mediterranean limpets, the Leghorn population of Patella aspera had a greater degree of heterozygosity than the Irish ones studied by Wilkins ( $H_{0}$ for Leghorn population was $0.437 ; H_{0}$ from Wilkins' data for Kilkee and Crosshaven populations were 0.277 and 0.234 , respectively). On the basis of the $H_{0}$ values the Leghorn population of $P$. lusitanica is more variable at the PGI locus than $P$. aspera and $P$. coerulea, and hence more than $P$. vulgata.

The PGI electrophoretic patterns in Patella aspera and $P$. coerulea were much alike. In both species virtually the same alleles were observed by us. The general zone of mobility of the PGI allozymes is more anodal for $P$. lusitanica than for $P$. aspera and $P$. coerulea, although the former shares with the other species one of its less frequent electrophoretic phenotypes. Moreover we have some data (paper in preparation) showing that PGI allozymes of $P$. Iusitanica are significantly more active than those of the other two Mediterranean species, although such allozymes show the same thermostability.

The differences of Patella Iusitanica pattern may tentatively be interpreted as a result of a selective action, which interfered with the ecological overlap in the same zone where this species coexists with the others, and enabled it to extend its vertical range 
further upwards. Unlike other species, $P$. lusitanica exhibits specific morphological (Bannister, 1975) and physiological (Davies, 1967) adaptations at the upper intertidal zone. Hence the discrepancy in the electrophoretic distribution of PGI allozymes between $P$. lusitanica on the one hand and $P$. aspera- $P$. coerulea on the other, would reflect differences in some niche parameters of the different habitats colonized by them.

The PGI pattern similarity between Patella aspera and $P$. coerulea could mean - as their high morphometric overlap - that both these species are subjected to the same selective action, since they colonize the same littoral zone in Leghorn. This finding is being confirmed by our observations on infralittoral populations of $P$. aspera and $P$. coerulea, from Ischia near Naples, Italy (paper in preparation). Their coexistence in the lower intertidal zone is possible because they do not compete with each other for food resources; in fact, even a cursory examination shows that the gut content definitely differs between the two species, being rich in lithothamnia only in $P$. aspera. According to Murphy (1976), who studied the LAP locus variability in some species of American limpet Acmaea, the lack of competition might account for the similarity of the electrophoretic pattern of an enzyme in coexisting species.

Also Mytilus edulis, an eurytopic species, when in sympatry with $M$. californianus, is found above the zone of the other species (Levinton and Suchaneck, 1978), like Patella lusitanica with respect to the other two Mediterranean species. It is interesting that also in M. edulis, as in P. lusitanica, compared to P. aspera and $P$. coerulea, the general zone of mobility of PGI allozymes is more anodal than in $M$. californianus.

The Atlantic limpet Patella vulgata and the Atlantic populations of $P$. aspera, which, despite the breadth of their ecological niches, are often sympatric, differ in their PGI alleles, which moreover encode enzyme variants showing different thermostability characteristics (Wilkins, 1977). Wilkins relates these differences to the different environmental temperatures experienced by the two species in their vertical ranges.

Evidence is provided by our results on PGI allozymes thermostability that at least the most common enzyme variants have the same resistance to high temperatures both in Patella vulgata from Roscoff and in Mediterranean $P$. aspera. The PGI allozymes of the other Patella species studied by us also exhibit the same degree of thermostability. This result suggests that in the differentiation process of the PGI locus in mediterranean limpets one or more factors other than temperature have been involved, and furthermore that the enzyme thermostability at high temperatures is not a sufficient condition to conquer the upper intertidal zone.

Lastly, since comparison of Wilkins' (1977) findings with the present ones reveals that the most frequent allozyme of the Irish Patella aspera has a more limited thermostability as compared to the allozymes of the Mediterranean P. aspera, the Atlantic and Mediterranean populations may reasonably be assumed to be genetically different, as far as the PGI locus is concerned.

Acknowledgements. The authors wish to express their thanks to Professor G. Bacci for critical discussion of this work, and to Professor B. Battaglia for reviewing the manuscript. We also wish to thank Mrs. G. Celebrano for technical assistance.

\section{LITERATURE CITED}

Ayala, F. J., Hedgecock, D., Zumwalt, G. S., Valentine, J. W. (1973). Genetic variation in Tridacna maxima, an ecological analog of some unsuccessful evolutionary lineages. Evolution, Lancaster, Pa. 27: 177-191

Bacci, G., Sella, G. (1970). Correlations between characters and environmental conditions in Patella of coerulea group. Pubbl. Staz. zool. Napoli 38: 1-17

Bannister, J. V. (1975). Shell parameters in relation to zonation in mediterranean limpets. Mar. Biol. 31: 63-67

Branch, G. M., Newell, R. C. (1978). A comparative study of metabolic energy expenditure in the limpets Patella cochlear, P. oculus and P. granularis. Mar. Biol. 49: 351-361

Brian, M. V., Owen, G. (1952). The relation of the radula fraction to the environment in Patella. J. Anim. Ecol. 21: 241-249

Davies, P. S. (1967). Physiological ecology of Patella. II. Effect of environmental acclimatation on the metabolic rate. J. mar. biol. Ass. U. K. 47: 61-74

Davies, P. S. (1969). Effect of environment on metabolic activity and morphology of Mediterranean and British species of Patella. Pubbl. Staz. zool. Napoli 37: 641-656

Evans, R. G. (1958). The genus Patella on the west coast of France. J. Conch., Paris 98: 126-151

Fischer-Piette, E., Gaillard, J. (1959). Les patelles au long des côtes atlantiques iberiques et nord-marocaines. J. Conch., Paris 99: 135-200.

Kimura, M., Crow, J. F. (1964). The number of alleles that can be maintained in a finite population. Genetics, Austin, Tex. 49: 725-738

Levinton, J. (1973). Genetic variation in a gradient of environmental variability: marine Bivalvia (Mollusca). Science, Wash. 180: 75-76

Levinton, J. S. (1975). Levels of genetic polymorphism at two enzyme encoding loci in eight species of the genus Macoma (Mollusca: Bivalvia). Mar. Biol. 33: 41-47

Levinton, J. S., Suchaneck, T. H. (1978). Geographic variation, niche breadth and genetic differentiation at different geographic scales in the mussels Mytilus californianus and $M$. edulis. Mar. Biol. 49: 363-375

Murphy, P. G. (1976). Electrophoretic evidence that selection reduces ecological overlap in marine limpets. Nature, Lond. 261: 228-230

Pérès, J. M., Picard, J. (1964). Nouveau manuel de bionomie bentique de la mer Méditerranée. Recl Trav. Stn mar. Endoume 31: 1-137

Schaal, B. A., Anderson, W. W. (1974). An outline of techniques for starch gel electrophoresis of enzymes from the American oyster Crassostrea virginica Gmelin. Ga mar. Sci. Center, Tech. Rep. Ser. 74: 3-19

Sella, G. (1976). Biometrical relationships between mesolitto- 
ral and infralittoral Patella populations in the Mediterranean. Pubbl. Staz. zool. Napoli 40: 123-132

Sella, G., Bacci, G. (1971). Relationships between mesolittoral and infralittoral Patella populations in the Mediterranean Pubbl. Staz, zool. Napoli 39: 87-106

Snedecor, G. W., Chochran, W. G. (1967). Statistical methods, The Iowa State University Press, Ames, pp. XIV-593

Snyder, T. P., Gooch, J. L. (1973). Genetic differentiation in Littorina saxatilis (Gastropoda). Mar. Biol. 22: 177-182

Tracey, M. L., Bellet, N. F., Gravem, C. D. (1975). Excess allozyme homozygosity and breeding population structure in the mussel Mytilus californianus. Mar. Biol. 32: 303-311
Vermeij, G. J. (1973). Morphological patterns in high-intertidal gastropods: adaptive strategies and their limitations. Mar. Biol. 20: 319-346

Wilkins, N. P. (1975). Phosphoglucose isomerase in marine molluscs. In: Markert, C. L. (ed.) Isozymes, IV Academic Press, New York, pp. 931-943

Wilkins, N. P. (1977). Genetic variability in littoral gastropods: phosphoglucose isomerase and phosphoglucomutase in Patella vulgata and P. aspera. Mar. Biol. 40: 151-155

Wilkins, N. P., Mathers, N. F. (1974). Phenotypes of phosphoglucose isomerase in some bivalve molluscs. Comp. Biochem. Physiol. 48 B: 599-611

This paper was presented by Professor B. Battaglia; it was accepted for printing on February $14,1980$. 